\title{
Investigation of the Patients with Angioedema who Applied to the Emergency Department
}

\author{
(1) Ayșe Ertekin ${ }^{1}$, (1) Șerife Özdinçำ, (1) Ömer Levent Avșaroğulları²
}

1Department of Emergency Medicine, Afyonkarahisar Health Sciences University Faculty of Medicine, Afyonkarahisar, Turkey 2Department of Emergency Medicine, Erciyes University Faculty of Medicine, Kayseri, Turkey

\begin{abstract}
Aim: This study aimed to describe the demographic and clinical characteristics of patients with angioedema admitted to the emergency department.

Materials and Methods: This prospective study was conducted in the Emergency Medicine Department of Erciyes University Medical School between April 15 and November 30, 2016. Patients older than 18 years presenting with angioedema were included in the study. The demographic and clinical data of the patients were then analyzed.

Results: This study included 100 patients with angioedema and the mean age of $41.48 \pm 14.10$ years. Forty-five percent of the patients were experiencing their first attack. The most frequent complaints were swelling (93\%) and itching and redness (54\%). Edema was typically observed in the periorbital region and on the lips. Drug use (52\%) was the most frequent cause of angioedema, with the use of nonsteroidal antiinflammatory drugs being the most common drug-related cause (23\%). All the patients received antihistamine and steroid therapy. Although most patients were administered adrenaline (67\%), some were administered fresh frozen plasma and complement 1 inhibitor concentrate (3\%). Furthermore, the dermatology department was consulted for most of the patients (89\%).

Conclusion: Angioedema is a medical condition that requires hospitalization in most cases and has the potential to rapidly progress into a life-threatening stage. Therefore, the timely recognition and appropriate management of this clinical condition in the emergency department is of great importance.
\end{abstract}

Keywords: Angioedema, emergency department, urticaria, complement 1 inhibitor

\section{Introduction}

Angioedema (AE) is a clinical presentation that usually manifests itself as a transient, localised, subcutaneous or submucosal nonpitting edema in the tongue, mouth, lips, larynx, and face $(1,2)$. Tissue swelling is caused by a sudden increase in wall permeability of the vessels in the skin and submucosa (3). AE is a non-pitting type of edema, is not affected by gravity and is often asymmetrical. This type of edema is not itchy, usually no pain, but a feeling of burning or tingling might be observed (4). It may progress very quickly and may lead to swelling of the mouth, tongue, and larynx, leading to a respiratory-tract obstruction, thus might evolve into a life-threatening condition (5). If the gastrointestinal tract is affected, severe nausea, vomiting, and abdominal pain may be seen $(1,6)$. Imaging methods can be used in patients with acute symptoms affecting the neck and abdominopelvic region (7). It is categorised as allergic (mast cell or immunoglobulin E (IgE) mediated) or non-allergic (mediated by bradykinin) (8). Allergic AE is usually accompanied by urticaria. Different types of food, insecticides and drugs are the allergens that cause this type of IgE-mediated reactions (9). Non-allergic AE can be classified as; hereditary $\mathrm{AE}(\mathrm{HAE})$, acquired $\mathrm{AE}$, angiotensin-converting enzyme inhibitor (ACEI)-related AE, pseudoallergic $\mathrm{AE}$, and idiopathic $\mathrm{AE}$ (8).

$A E$ is an urgent clinical condition which requires visiting emergency departments (ED). Emergency physicians may encounter various presentations of this clinical entity which 
may have life-threatening potential. The aim of this study is to investigate clinical and demographic properties of the patients presenting to the ED due to $\mathrm{AE}$ in particular and to detect the outcomes.

\section{Materials and Methods}

This prospective study was carried out in the Emergency Medicine Department of Erciyes University Medical School between April 15, 2016 and November 30, 2016. The study was approved by the Ethics Comittee of Erciyes University (protocol no: 2016/212). Those patients older than 18 years and presenting with AE were included in the study. The patients that were involved in the study, were informed about the scope of this study, and their informed consents were obtained. A total of 100 patients was included in the study. The following data were recorded in prepared forms: age, sex, occupation, time of the first episode, the number of attacks, medical history, history, medications used regularly by the patient, chief complaint, vital signs, and other conditions that might have an association with AE (eg pregnancy, menstruation, hormone replacement, drug use, smoking, alcohol use, trauma, infection, anxiety, physical stress, food intake, operation, tooth extraction, insect bite, contrast agent exposure), physical examination findings, consultations, treatment in the ED, response to the treatment, and outcome (admission or discharge).

\section{Statistical Analysis}

Descriptive statistics (mean, median, percent, standard deviation) was used in the analysis of the data. Normal distribution of the continuous data was assessed by the Kolmogorov-Smirnov and Shapiro-Wilk tests. The Mann-Withney $U$ test was used to compare the median values of the two independent groups, and the Kruskal-Wallis test was used to compare the median values of the multiple independent groups. The chi-square test was used to compare the per cent distributions of the categorical data. The evaluations were performed in the SPSS V20 program and $p<0.05$ value was considered significant.

\section{Results}

Between 15.04.2016 and 30.11.2016, patients older than 18 years of age who were admitted to the ED with AE among all adult admissions were investigated. The mean age of the patients was $41.48 \pm 14.097$ years (19-86), 46 of the 100 patients were female. The most frequent of the ED visits were in April (28\%) and May (23\%), especially during the seasonal transition periods (AprilMay and September) (Table 1).

Forty-nine percent of the patients were employed, and 51\% of them were not working in a job. The most frequent occupational group in the working group was civil servant (23\%), and among the non-working group was housewife (35\%). Urticaria was not present in the $78 \%$ of the patients with AE who were referred to the ED. When the effect of the gender on this parameter was investigated, urticaria was detected in $45.5 \%$ of male patients and $54.5 \%$ of female patients. There was no statistically significant difference between genders with respect to the presence or absence of urticaria in the patients with $\mathrm{AE}$ in the study $(p=0.363)$, (Table 2 ).

When the effects of the seasonal differences are assessed on the occurrence of urticaria in patients with $\mathrm{AE}$, no statistically significant difference was found between the seasons $(p=0.40)$. Admission time of the patients in the study group to the ED is

\begin{tabular}{|l|l|}
\hline Table 1. The frequency of angioedema by months \\
\hline Months & $\begin{array}{l}\text { Percentage value } \\
\text { of the number of } \\
\text { patients (\%) }\end{array}$ \\
\hline April & 28 \\
\hline May & 23 \\
\hline June & 18 \\
\hline July & 7 \\
\hline August & 2 \\
\hline September & 12 \\
\hline October & 5 \\
\hline November & 5 \\
\hline Total & $\mathbf{1 0 0}$ \\
\hline
\end{tabular}

Table 2. Dermographic data in angioedema groups with or without urticaria

\begin{tabular}{|c|c|c|c|c|}
\hline Demography & $\begin{array}{l}\text { AE Total } \\
(n=100)\end{array}$ & $\begin{array}{l}\text { AE without } \\
\text { urticaria } \\
(n=78)\end{array}$ & $\begin{array}{l}\text { AE with } \\
\text { urticaria } \\
(n=22)\end{array}$ & p \\
\hline \multicolumn{5}{|c|}{ Gender (number, \%) } \\
\hline Female & $46(46)$ & $34(43.6)$ & $12(54.5)$ & \multirow{2}{*}{0.363} \\
\hline Male & $54(54)$ & $44(56.4)$ & $10(45.5)$ & \\
\hline \multicolumn{5}{|c|}{ Month of admission } \\
\hline Spring & $51(51)$ & $40(51.3)$ & $11(50.0)$ & \multirow{3}{*}{0.403} \\
\hline Summer & $27(27)$ & $19(24.4)$ & $8(36.4)$ & \\
\hline Autumn & $22(22)$ & $19(24.4)$ & $3(13.6)$ & \\
\hline
\end{tabular}

Admission time

\begin{tabular}{|l|l|l|l|l|}
\hline $24-12$ & $51(51)$ & $38(48.7)$ & $13(59.1)$ & 0.390 \\
\hline $12-24$ & $49(49)$ & $40(51.3)$ & $9(40.9)$ & 0.134 \\
\hline $\begin{array}{l}\text { Age } \\
\text { (mean } \pm \text { SD) }\end{array}$ & $41.48 \pm 14.09$ & $42.59 \pm 14.54$ & $37.55 \pm 11.85$ & 0.005 \\
\hline $\begin{array}{l}\text { Number of } \\
\text { attacks } \pm \text { SD }\end{array}$ & $4.06 \pm 7.53$ & $3.39 \pm 6.72$ & $6.40 \pm 9.70$ & \\
\hline \multicolumn{4}{|l|}{ AE: Angioedema, SD: Standard deviation, n: Number } \\
\hline
\end{tabular}


classified into two groups; between 12:00 p.m. - 12:00 a.m. and 12:00 a.m. - 24:00 p.m. There was no statistically significant effect of the admission time on the presence or absence of urticaria complaints in the patients with $\mathrm{AE}(\mathrm{p}=0.39)$, (Table 2).

It was found that $45 \%$ of the patients were experiencing their first attack on the initial admission. The mean number of attacks in all AE patients was calculated as $4.06 \pm 7.53$. When the number of attacks was evaluated according to the presence of urticaria, the average number of attacks was $6.40 \pm 9.70$ for patients with urticaria and $3.39 \pm 6.72$ for patients without urticaria. A statistically significant difference was noted between the two groups ( $p=0.005$ ) (Table 2). The mean number of AE episodes in patients with anxiety-related AE was found to be higher than that of the ones without it $(p=0.002)$.

The most frequent chronic diseases in the patients' medical history were atopy (31\%), urticaria (22\%) and hypertension (12\%). There were 4 cases with the history of HAE. The most frequent complaints in our study were swellings in the body. Edema was most frequently detected in the periorbital region and lips (48\%), (Table 3). We identified the most frequent cause among the factors leading to the development of the onset as medications by $52 \%$. No triggering factor was identified in $34 \%$ of the cases. The most common type of drug (23\%) in drug-induced AE were non stereoidal anti inflammatory drugs (NSAID)s (Table 4). Dexketoprofen (7\%) was the most common cause of the AE among the NSAID's (Table 5). Ten percent of the patients in the study were experiencing tachypnea, $2 \%$ was hypotensive, and in 12 of the patients, eosinophilia was detected in the laboratory findings.

All patients received antihistamine and steroid therapy. Adrenalin was administered in $67 \%$ of patients whereas fresh frozen plasma and complement 1 inhibitor ( $\mathrm{C} 1 \mathrm{INH})$ were given in 3\% of patients. $89 \%$ of the patients were consulted the dermatology department. Seventy-three of the patients who were consulted were hospitalised. None of the patients' clinical prognosis was critical or mortal.

\section{Discussion}

Rapid admission and evaluation of the AE patients by an Emergency Medicine Physician along with identification of the coincidental findings and initiation of the treatment as soon as possible are of utmost importance. The most appropriate treatment should be determined by the clinical presentation and underlying pathophysiological mechanism (4). Zingale et al.

\begin{tabular}{|l|l|l|l|l|}
\hline Table 3. Symptoms and findings of physical examination associated with angioedema \\
\hline Symptoms & $\begin{array}{l}\text { AE Total } \\
(\mathbf{n = 1 0 0 )}\end{array}$ & $\begin{array}{l}\text { AE without urticaria } \\
(\mathbf{n = 7 8})\end{array}$ & $\begin{array}{l}\text { AE with urticaria } \\
(\mathbf{n = 2 2})\end{array}$ & $\mathbf{p}$ \\
\hline Itching & $54(54)$ & $40(51.3)$ & $14(63.6)$ & 0.304 \\
\hline Erythema & $53(53)$ & $37(47.4)$ & $16(72.7)$ & 0.036 \\
\hline Swelling & $93(93)$ & $72(92.3)$ & $21(95.5)$ & 0.609 \\
\hline Shortness of breath & $28(28)$ & $22(28.2)$ & $6(27.3)$ & 0.931 \\
\hline Abdominal pain & $4(4)$ & $1(1.3)$ & $3(13.6)$ & 0.009 \\
\hline Nausea & $4(4)$ & $4(5.1)$ & $0(0)$ & 0.278 \\
\hline Vomiting & $1(1)$ & $1(1.3)$ & $0(0)$ & - \\
\hline Diarrhea & $0(0)$ & $0(0)$ & $0(0)$ & - \\
\hline Anaphylaxis & $2(2)$ & $2(2.6)$ & $0(0)$ & 0.128 \\
\hline Changes in consciousness & $0(0)$ & $0(0)$ & $0(0)$ & - \\
\hline Physical examination & & & & \\
\hline Periorbital edema & $48(48)$ & $39(50.0)$ & $9(40.9)$ & 0.451 \\
\hline Edema in the lips & $48(48)$ & $38(48.7)$ & $10(45.5)$ & 0.787 \\
\hline Macroglossia & $4(4)$ & $3(3.8)$ & $1(4.5)$ & 0.882 \\
\hline Edema of the uvula & $43(43)$ & $37(47.4)$ & $6(27.3)$ & 0.092 \\
\hline Extremity findings & $37(37)$ & $25(32.1)$ & $12(54.5)$ & 0.050 \\
\hline Abdominal findings & $1(1)$ & $1(1.3)$ & $0(0)$ & 0.594 \\
\hline Genital findings & $0(0)$ & $0(0)$ & $0(0)$ & - \\
\hline Respiratory system findings & $2(2)$ & $2(2.6)$ & $0(0)$ & 0.448 \\
\hline AE: Angioedema, n: Number & & & \\
\hline
\end{tabular}




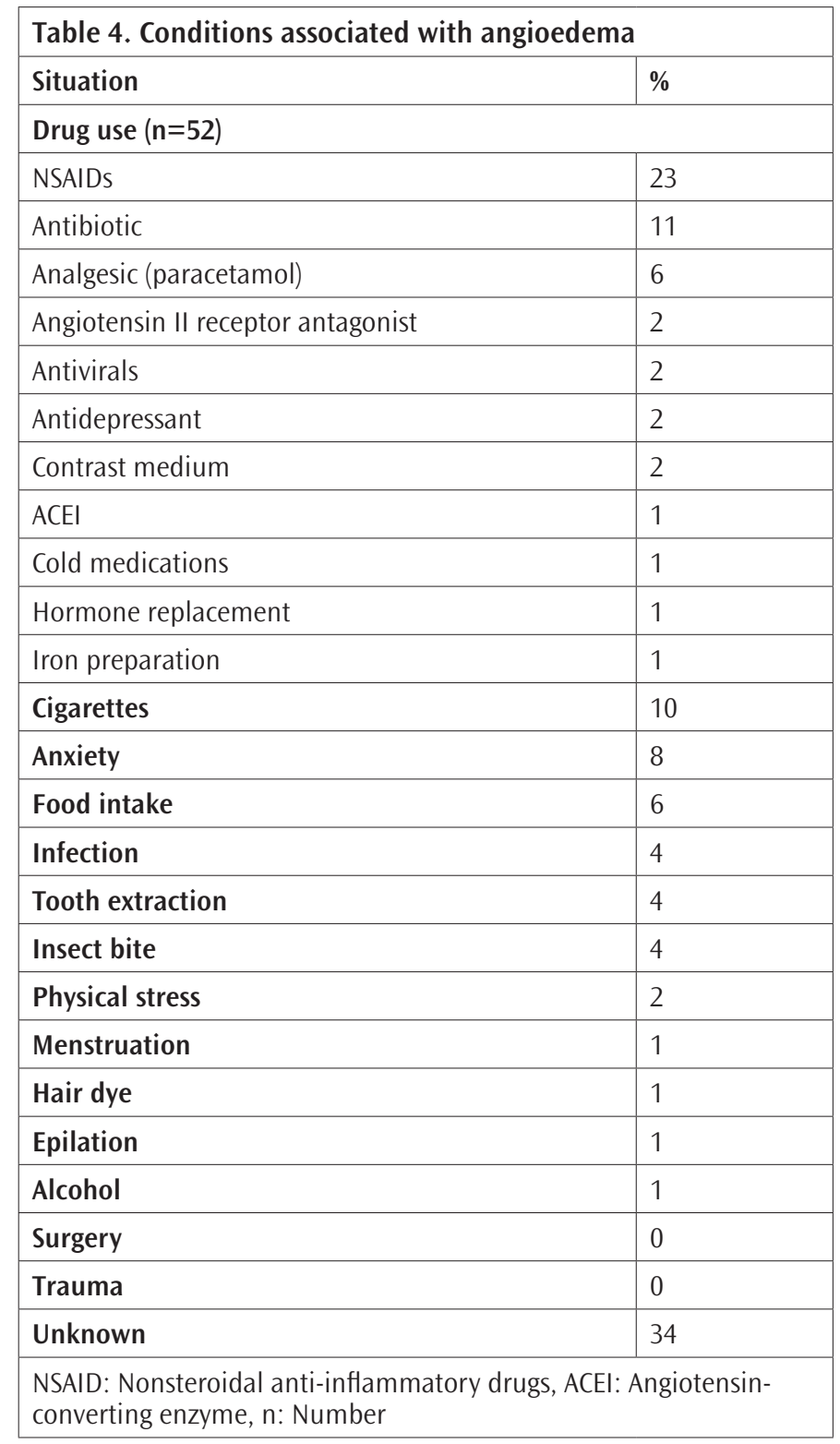

(10) conducted a study between 1993 and 2003, classifying 776 patients with AE who were admitted to the hospital, according to the different causes of their AE. They reported triggering causes of the AE as following: due to external causes (medications, insect bite or food intake) was seen in 124 patients (16\%), due to ACEI usage was observed in 85 patients (11\%), AE due to autoimmunity or infections in 55 patients (7\%), due to $\mathrm{C} 1 \mathrm{INH}$ deficiency in 197 patients (25\%), and in 315 patients (41\%) there was not any identified cause (10). According to our study, patients with AE due to allergies, were found to have the following triggering factors, insect stings (bee) 4\%, food intake (fish and spice consumption) $6 \%$, drug use $24 \%$ (antibiotics $11 \%$, analgesics $6 \%$, antivirals and antidepressants $2 \%$, cold medications $1 \%$, hormone replacement and iron preparation 1\%), and in $1 \%$ of the patients there was the history of application of hair dye and epilation. In patients
Table 5. Percentage of the drugs that cause angioedema compared to the active ingredients

\begin{tabular}{|l|l|}
\hline Drug-active substance & $\%$ \\
\hline Analgesics & 1 \\
\hline Etodolac & 1 \\
\hline Metamizole sodium & 1 \\
\hline Naproxen sodium & 1 \\
\hline Parasetamolklorfeniraminmaleat & 1 \\
\hline Acetamidine & 2 \\
\hline Acetylsalicylic acid & 2 \\
\hline Feniramidol HCL & 2 \\
\hline Diclofenac sodium & 3 \\
\hline Flurbiprofen & 3 \\
\hline Ibuprofen & 6 \\
\hline Paracetamol & 1 \\
\hline Dexketoprofen & 1 \\
\hline Antibiotics & 1 \\
\hline Doxycycline & 1 \\
\hline Sefuroximeacetyl & 1 \\
\hline Amoxicillin & 1 \\
\hline Gemifloxacin & 1 \\
\hline Moxifloxacin & 2 \\
\hline Trimethoprim sulfamethoxazole & 1 \\
\hline Penicillin & 2 \\
\hline Ciprofloxacin & 1 \\
\hline Antihypertensives & 1 \\
\hline Fosinopril & 1 \\
\hline Olmesartanmedoxomil & 1 \\
\hline Olmesartanmedoximilhydrochlorothiazide & 1 \\
\hline Iron preparation & 1 \\
\hline Progesterone & 1 \\
\hline Bupropion HCL & 1 \\
\hline Escitalopram & 1 \\
\hline Acyiclovir & 1 \\
\hline HCL: Hydochloride & 1 \\
\hline
\end{tabular}

without allergies the causative agents were classified as, ACEI usage in $1 \%$, ARB2 antagonists in $2 \%$, NSAIDs in $23 \%$, contrast dye in $2 \%$. In $34 \%$ of the patients, there was no identified agent and they were classified as idiopathic. Four patients had a history of HAE. $4 \%$ of the patients who admitted concurrently had a history of infection and/or tooth extraction. We think that the differences between our study and the causes of the AE in other studies are due to the differences in the cultural structure 
(nutrition habits, education levels), the time and duration of the study, the geographical conditions in which the studies have been made, and the way of life of the societies (village and city type life).

Bork et al. (11) reported that 221 patients with C1 INH deficiency were presented with edema in the extremities, face, genitalia or trunk in $97.4 \%$ of the time. Edema in the periorbital area (48\%) and the lip (48\%) was the most common locations in our study, whereas uvula edema was seen in $43 \%$, edema in the extremities was observed in $37 \%$, macroglossia was found in $4 \%$, respiratory system findings in $2 \%$, and findings in the abdomen in $1 \%$. Genital involvement was not detected in any patient. We think that the differences between the studies are due to individual reasons.

In a study conducted by Champion et al. (12), it was found that $49 \%$ of 554 urticaria patients were accompanied by AE, and $11 \%$ of patients had AE alone. In our study, 22\% of the patients were accompanied by urticaria. There are differences in the presence or absence of urticaria in patients with AE in these studies. We think that this difference is due to the fact that the causes of $\mathrm{AE}$ (allergic or non-allergic) are different. It has been reported in the literature that the co-occurrence rate of urticaria and AE caused by allergies, is higher (8).

The most common medications in the drug-related AE are; NSAIDs, ACEI, angiotensin II receptor antagonists, antibiotics, radiocontrast agents, proton pump inhibitors, statins, fibrinolytic agents, estrogens, diuretics, calcium channel blockers and psychotropic drugs. Acetylsalicylic acid and ibuprofen are appeared to be at the forefront of the NSAIDs. NSAID and acetylsalicylic acid intolerance are seen in $0.3-0.9 \%$ of the population. However, there are no exact figures for the incidence of AE due to NSAIDs and acetylsalicylic acid (13). In our study, it was determined that the most common cause of AE was drug use, with $52 \%$. The use of dexketoprofen (7\%) was the most common cause of the AE among the NSAID's. Among other NSAID drugs as $A E$ triggers, the following percentages were recorded: flurbiprofen and ibuprofen 3\%, diclofenac sodium, acetylsalicylic acid and feranimadol $\mathrm{HCl} 2 \%$, etodolac, metamizole sodium, naproxen sodium and acetaminin $1 \%$.

ACEl-related AE is independent of the dose, can be seen with the initial administration of ACEl's, as well as months or years later. They are the most frequent cause of the recurrent drugrelated $A E(13,14)$. Banerji et al. (15) found that $30 \%$ of the 220 AE patients who applied for emergency services was due to ACEI usage. The most common findings in these patients were reported as: shortness of breath, lip and tongue swelling and laryngeal edema. In our study; the ACEI Fosinopril (1\%) and the angiotensin II receptor antagonist Olmesartanmedoxomil (2\%) were found to cause $\mathrm{AE}$ clinical signs and symptoms after many years of usage. Patients were admitted to our ED between 6.00 p.m. and 9.00 p.m. with complaints of lipedema, macroglossia, uvula edema. One of the patient's AE was accompanied by urticarial lesions. Two of our patients were admitted to the dermatology department. Our other patient, whose clinical signs and symptoms were regressed, and was discharged after observation ( $<24$ hours).

Iwamoto et al. (16) studied the patients with HAE in Japan in 2009; $54 \%$ of patients with HAE type I and II had swelling, $42 \%$ had a feeling of discomfort in the throat, and 37\% had abdominal complaints. In the European Hereditary Angioedema Burden Research's survey conducted with HAE patients, it was determined that 73 of the patients were working full-time, 21 of the patients were working part-time, seven of the patients were studying, and 19 of the patients were both studying and working (17). Huang (18) reported in a study that was conducted with 63 patients with HAE in 2004 that, the patients were admitted to the ED with an average of 4.7 times per year, and in one-quarter of the patients, anaphylaxis was seen in the ED. Iwamoto et al. (16) conducted a study in HAE patients in Japan and reported that: $54 \%$ of patients with HAI type I and II had swelling, $42 \%$ had a feeling of discomfort in the throat, and 37\% had abdominal complaints. In another study, C1 INH concentrate therapy was administered to $29 \%$ of patients who applied with an acute exacerbation of $\operatorname{HAE}(13,16)$. There were only four male patients with a history of HAE with the mean age of 36.75 in the 100 AE patients included in our study. All of our patients with HAE also had an HAE history in their family. Two patients were admitted to the hospital ED with twenty-fifth acute exacerbation of $\mathrm{AE}$, the other two patients were admitted with their third attack. It was learned that $\mathrm{C} 1 \mathrm{INH}$ concentrate was available in the patients' home. Two patients with lip edema, one patient with uvula edema and one patient with periorbital edema were admitted to our ED. A patient with edema on the lips also had urticarial lesions. The clinical presentation of two HAE patients was triggered by anxiety, and the triggering causes of the other two were unknown. Only one patient was treated with $\mathrm{C} 1 \mathrm{INH}$ concentrate. Three patients were admitted to the dermatology department, and one patient was discharged after 24 hours of observation in the ED. When we looked at the occupational status of these four patients, we learned that two of them are civil servants and the others were tradesmen with their own business. At least 24 hours of daily activity and workforce productivity were lost after the ED admissions of these patients. When our patients with HAE were evaluated; were consistent with the literature concerning the loss of workforce, symptom similarity at the time of application, methods applied during treatment, follow-up time in the hospital, and results $(13,16,17)$. 
In the AHRQ-HCUP 2007 National Emergency Service Example, the number of patients referred to the Emergency Service with AE was 112,105 per year. It has been reported that $45 \%$ of HAE patients and $18.3 \%$ of AE patients are admitted to the inpatient clinic (19). During our 7-month study in 2016 in the Emergency Medicine Department of Erciyes University Medical School only $4 \%$ of AE patients had an HAE history during this time period. Seventy-three per cent of the $100 \mathrm{AE}$ patients that are included in the study group were hospitalized, and $27 \%$ were treated and discharged within the emergency care.

\section{Conclusion}

In the light of all these findings, even though AE patients are not frequently encountered in emergency services, patients' clinical signs and symptoms may worsen rapidly, and AE can be mortal. Simultaneous evaluation and treatment of the patients would be life-saving. The deepening of information about the anamnesis, personal and family medical history of AE patients by emergency medicine physicians can help to classify the disease, thus allowing to determine the most appropriate treatment approach. In addition to this, the factors such as medication use, anxiety, and taking preventive measures during the transition seasons can cause great benefit in protecting patients from attacks.

\section{Acknowledgements}

This research was produced from Ayșe Ertekin's thesis of expertise in medicine named "Evaluation of The Patients Who Apply to The Emergency Department with Angioedema".

\section{Ethics}

Ethics Committee Approval: The study was approved by Ethics Comittee of Erciyes University and was conducted in accordance with the principles of the Declaration of Helsinki (protocol no: 2016/212).

Informed Consent: An informed consent form was obtained from each patient.

Peer-review: Externally peer-reviewed.

\section{Authorship Contributions}

Surgical and Medical Practices: A.E., Concept: A.E., Ö.L.A., Design: Ö.L.A., Data Collection or Processing: A.E., Ö.L.A., S..̈., Analysis or Interpretation: A.E., S..̈., Literature Search: A.E., Writing: A.E., S..̈.

Conflict of Interest: The authors declared no potential conflicts of interest with respect to the research, authorship, and/or publication of this article.
Financial Disclosure: The authors received no financial support for the research, authorship, and/or publication of this article.

\section{References}

1. Satkiene D, Kavoliuniene A, Petrauskiene I, Sirvyte R. Tongue angioedema associated with angiotensin-converting enzyme inhibitor (diagnosis, differential diagnosis, treatment). Medicina (Kaunas). 2003;39:570-3.

2. Wilkerson RG. Angioedema in the emergency department: an evidencebased review. Emerg Med Pract. 2012;14:1-21.

3. Bernstein JA, Moellman J. Emerging concepts in the diagnosis and treatment of patients with undifferentiated angioedema. Int J Emerg Med. 2012;6;5:39.

4. Jaiganesh T, Wiese M, Hollingsworth J, Hughan C, Kamara M, Wood P, et al. Acute angioedema: recognition and management in the emergency department. Eur J Emerg Med. 2013;20:10-7.

5. Cicardi M, Bellis P, Bertazzoni G, Cancian M, Chiesa M, Cremonesi P, et al. Guidance for diagnosis and treatment of acute angioedema in the emergency department: consensus statement by a panel of Italian experts. Intern Emerg Med. 2014;9:85-92.

6. Vázquez Nava F, Almeida Arvizu VM, Sánchez Nuncio HR, de los Angeles Villanueva Carreto M, Fogelbach Guidos GA. Prevalence and potential triggering factors of chronic urticaria and angioedema in an urban area of northeastern Mexico. Rev Alerg Mex. 2004;51:181-8.

7. Gakhal MS, Marcotte GV. Hereditary angioedema: imaging manifestations and clinical management. Emerg Radiol. 2015;22:83-90.

8. Lewis LM. Angioedema: etiology, pathophysiology, current and emerging therapies. J Emerg Med. 2013;45:789-96.

9. Sin A. Acute urticaria and angioedema. 7th National Internal Medicine Congress. 2005; 16-20 September.

10. Zingale LC, Beltrami L, Zanichelli A, Maggioni L, Pappalardo E, Cicardi B, et al. Angioedema without urticaria: a large clinical survey. CMAJ. 2006;175:106570

11. Bork K, Meng G, Staubach P, Hardt J. Hereditary angioedema: new findings concerning symptoms, affected organs, and course. Am J Med. 2006;119:26774

12. Champion RH, Roberts SOB, Carpenter RG, Roger JH. Urticaria and angioedema: a review of 554 patients. Br J Dermatol. 1969;588-97.

13. Inomata N. Recent Advances in Drug-InducedAngioedema. Allergol Int 2012;61:545-57.

14. Kaplan AP, Greaves MW. Angioedema. Am Acad Dermatol. 2005;53:373-88

15. Banerji A, Clark S, Blanda M, LoVecchio F, Synder B, Camargo CA Jr. Multicenter study of patients with angiotensin-converting enzyme inhibitorinduced angioedema who present to the emergency department. Ann Allergy Asthma Immunol. 2008;100:327-32.

16. Iwamoto K, Mihara S, Ikezawa Z, Hide M. National prevalence survey of hereditary angioedema in Japan. Arerugi. 2011;60:26-32.

17. Aygören-Pürsün E, Bygum A, Beusterien K, Hautamaki E, Sisic Z, Wait S, et al. Socioeconomic burden of hereditaryangioedema: results from the hereditary angioedema burden of illness study in Europe. J Orphanet J Rare Dis. 2014;9:99.

18. Huang SW. Results of an on-line survey of patients with hereditary angioedema. Allergy Asthma Proc. 2004;25:127-31.

19. Zilberberg MD, Jacobsen T, Tillotson G. The burden of hospitalizations and emergency department visits with hereditary angioedema and angioedema in the United States, 2007. Allergy Asthma Proc. 2010; 31:511-9. 